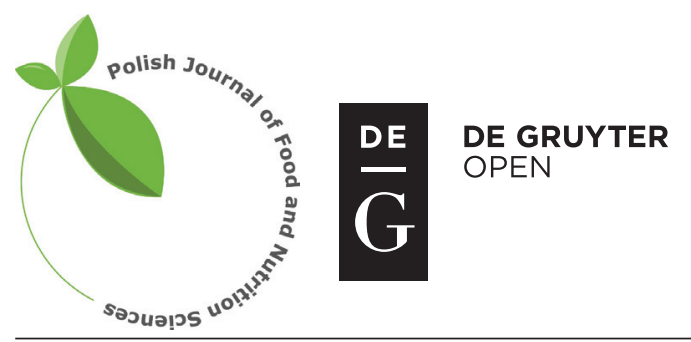

Pol. J. Food Nutr. Sci., 2017, Vol. 67, No. 2, pp. 123-128

DOI: $10.1515 /$ pjfns-2016-0012 http://journal.pan.olsztyn.pl

Original research article

Section: Food Quality and Functionality

\title{
Effect of pH Changes on Antioxidant Capacity and the Content of Betalain Pigments During the Heating of a Solution of Red Beet Betalains
}

\author{
Katarzyna Mikołajczyk-Bator ${ }^{1 *}$, Janusz Czapski ${ }^{2}$ \\ ${ }^{1}$ Department of Natural Science and Quality Assurance, Faculty of Commodity Science, \\ Poznań University of Economics and Business, al. Niepodlegtości 10, PL -61-875 Poznań, Poland \\ ${ }^{2}$ Institute of Food Technology of Plant Origin, Poznan University of Life Sciences, \\ al. Niepodlegtości 10, PL-61-875 Poznań, Poland
}

Key words: red beet, betalain pigments, antioxidants, $\mathrm{pH}$, heating

Red beets and their products are mainly consumed after processing. In this study, the effect of $\mathrm{pH}$ on changes in antioxidant capacity (AC) and the content of betalain pigments were analysed during the heating of a betalain preparation solution. With $\mathrm{pH}$ ranging from 4 to 9 during the heat-treatment, the content of red pigments decreased depending on the $\mathrm{pH}$ level of the sample. The losses of red pigments in the investigated betalain preparation solution increased along with rising $\mathrm{pH}$ levels of the heated solution. The greatest losses were recorded at $\mathrm{pH}$ of 9.0. An opposite correlation was observed for yellow pigments. The content of yellow pigments in the heated betalain preparation solution was increasing along with increasing $\mathrm{pH}$. The most pronounced increase in the content of yellow pigments was found at $\mathrm{pH}$ of 6.5 and 7.0. At the same time, the heated betalain preparation solution was shown to exhibit a higher antioxidant capacity at $\mathrm{pH}$ of $6.0(14.9 \mu \mathrm{mol}$ Trolox $/ \mathrm{mL})$ than at pH of $4.0(12.6 \mu \mathrm{mol}$ Trolox $/ \mathrm{mL})$. It was observed that the increase in the antioxidant capacity in heated betalain preparation solutions with $\mathrm{pH}$ in the $6.0-6.5$ range occurred as a result of increased concentrations of neobetanin, assessed by HPLC, within the $\mathrm{pH}$ range from 5.0 to 6.5 .

\section{INTRODUCTION}

Red beet, both in its natural and processed forms, exhibits a high antioxidant capacity due to the content of betalain pigments [Zakharova \& Petrova, 1998; Pedreno \& Escribano, 2000; Kanner et al., 2001]. A high variation was observed in juices extracted from red beet in terms of their antioxidant capacity and contents of red and yellow pigments [Czapski et al., 2009]. Betacyanins (reddish to violet pigments) along with betaxanthins (yellow pigments) form a group of chromoalkaloids known as betalains. The pigments are classified as secondary metabolites having a different chemical structure from anthocyanin pigments due to the presence of two nitrogen atoms in the molecules of different betalain pigments. Betalains are synthesised from the amino acid tyrosine in plants of the order Caryophyllales, with the exception of two families: Caryophyllaceae and Molluginacea [Strack et al., 2003].

Red beets and their products are mainly consumed after processing. The process of heating at the $\mathrm{pH}$ of 6-7, i.e. close to the natural physiological $\mathrm{pH}$ of red beet juice, has been found to give rise to betalain degradation products displaying high levels of antioxidant activity [Czapski et al., 2009].

Betalain pigments are used for food colouring purposes. They have an advantage over anthocyanins as food colou-

\footnotetext{
* Corresponding Author: Tel.: (48 61) 656 9022;

E-mail: katarzyna.mikolajczyk-bator@ue.poznan.pl tural Station in Nochowo, Poland.

rants because their colour is maintained within the $\mathrm{pH}$ range from 3.0 to 7.0 [Herbach et al., 2006], whereas anthocyanins are only suitable for acidic food products with the $\mathrm{pH}$ below 3.5. In solutions with the $\mathrm{pH}$ of $4-6$, anthocyanin pigments are colourless.

The heating of a solution of purified betalains and beet juice either decreases or increases the content of betalain pigments and their antioxidant capacity (AC), depending on the $\mathrm{pH}$ level of juice or the betalain solution. Some of the degradation products of betalain pigments induce a change in the colour of the heated solution of betalain pigments, and contribute to an increased content of yellow pigments determined spectrophotometrically using the Nilsson's method. The aim of this study was to determine the effect of $\mathrm{pH}$ on changes in the antioxidant capacity (AC) and the content of betalain pigments during the heating of a betalain preparation solution.

\section{MATERIALS AND METHODS}

\section{Plant material}

The solution of a preparation of betalain pigments for study purposes was obtained from the juice of red beets of the "Chrobry" variety. Roots of red beet were supplied by the Spójnia Plant Breeding, Seed Production and Horticul- 


\section{Juice production}

Red beets were washed under running water and cut into pieces. Juice was then extracted using a "Juice Master Professional" juice maker (Zelmer Poland). The resulting juice was centrifuged $(10,000 \times g / 15 \mathrm{~min})$.

\section{Procedure for obtaining a preparation of betalain pigments}

The preparation of red pigments for the study was obtained by means of precipitation of pigments from red beet juice with 95\% ethyl alcohol, with the volumetric ratio between juice and alcohol equal to 1:7, followed by centrifugation at $10,000 \times g / 15 \mathrm{~min}$ and lyophilisation. The following lyophilisation conditions were applied: freezing of the solution down to the temperature of $-35^{\circ} \mathrm{C}$, drying at $+15^{\circ} \mathrm{C}$ for $17 \mathrm{~h}$.

Prior to assays, the lyophilised preparation was dissolved in distilled water (as specified under section $\mathrm{pH}$ of betalain solution).

\section{pH of betalain solution}

The lyophilised betalain preparation was dissolved in $2 \mathrm{~mL}$ of distilled water, which resulted in the red pigment content of $1.28 \mathrm{mg} / \mathrm{mL}$ and yellow pigment content of $0.32 \mathrm{mg} / \mathrm{mL}$ in the solution (Table 1), as determined by Nilsson's method [Nilsson, 1970]. In the next step, the solution was adjusted to the $\mathrm{pH}$ levels of $4.0,5.0,6.0,6.5,7.0,8.0$ and 9.0 by adding $5 \%$ citric acid solution or $10 \% \mathrm{NaOH}$.

\section{Heating of betalain solution}

Betalain solutions were transferred in $2 \mathrm{~mL}$ aliquots to 2-mL glass ampoules, sealed and heated at a temperature of $90^{\circ} \mathrm{C}$ for $30 \mathrm{~min}$, in a water bath without the access of light and then rapidly cooled to room temperature $\left(25^{\circ} \mathrm{C}\right)$.

\section{Antioxidant capacity of juice and betalain preparation solution}

The antioxidant capacity of the betalain preparation solution before and after heating was established using the method with the ABTS cation radical, which consists in the determination of the antioxidant capacity based on the scavenging rate of $\mathrm{ABTS}^{+}$radicals formed previously during chemical reactions with potassium peroxysulphate $\mathrm{K}_{2} \mathrm{O}_{8} \mathrm{~S}_{2}$. Radicals formed in this reaction are blue-green in colour, while the added antioxidants by reducing the ABTS cation radical (2,2'-azinobis-(3ethylbenzthiazoline-6-sulphonic acid) result in the fading of solution colour, the rate of which is dependent on the contents of antioxidants in the solution [Re et al., 1999]. A regression equation was formulated based on the linear dependence of the percentage reduction of the ABTS cation radical on the concentration of the betalain preparation solution. Coefficients from the regression equation of the tested solutions and from the standard curve established for Trolox were used to calculate TEAC values of the betalain preparation solution in $\mu \mathrm{mol}$ Trolox $/ \mathrm{mL}$ of the betalain preparation solution.

The antioxidant capacity of the betalain preparation solution was assessed with the ABTS, using a Helios Alfa spectrophotometer with a thermostated compartment (Thermo Electron Corporation).

\section{Determination of the content of betalain pigments}

The contents of betalain pigments were assayed by differential spectrophotometry according to Nilsson [1970], which enables determining contents of violet betacyanins and yellow betaxanthins. The betalain preparation was diluted with a phosphate buffer ( $\mathrm{pH}$ 6.5) and absorbance was measured at $476 \mathrm{~nm}$ for yellow pigments and at $538 \mathrm{~nm}$ for red pigments using a Helios Alfa spectrophotometer (Thermo Electron Corporation USA). The content of pigments was expressed in $\mathrm{mg} / \mathrm{mL}$ of the sample.

\section{Analytical HPLC separation}

The analytical separation of betalain pigments from the betalain preparation was performed by HPLC on the basis of the methodology proposed by Stintzing et al. [2002]. The areas of individual peaks generated by pigments contained in the juice and in the betalain preparation solution are represented in Figure 1. The pigments were identified by comparing retention times of individual peaks with reference data [Stintzing et al., 2002].

The samples were filtered through a Millex-LCR syringe filter unit (Millipore) with the pore size of $0.45 \mu \mathrm{m}$, and subjected to chromatographic analysis. HPLC assays were performed using a HPLC system from Thermo Separation, equipped with a Spectra System UV-VIS detector. Analytical separation of the samples was conducted in a Waters Spherisorb column measuring $4.6 \mathrm{~mm} \times 250 \mathrm{~mm}$, with octadecylsilane (ODS) stationary phase, filled with $5 \mu \mathrm{m}$-packing, in the reversed phase (RP) mode. HPLC conditions were as follows: Eluent A consisting of $0.2 \%$ TFA and $10 \% \mathrm{HCOOH}(63: 35 \mathrm{v} / \mathrm{v})$, and eluent $\mathrm{B}$ prepared by mixing $100 \%$ acetonitrile and $10 \% \mathrm{HCOOH}(80: 20, \mathrm{v} / \mathrm{v})$, flow rate $1 \mathrm{~mL} / \mathrm{min}$. The first $15 \mathrm{~min}$ were performed isocratically with $100 \% \mathrm{~A}$, followed by a linear gradient from 0 to $20 \% \mathrm{~B}$ in $60 \mathrm{~min}$.

Registration was performed across the visible light range. Readings for the red pigments were made at the wavelength of $540 \mathrm{~nm}$, for the yellow pigments - at $480 \mathrm{~nm}$, and for betalamic acid - at $405 \mathrm{~nm}$.

\section{Statistical analysis}

The data were evaluated statistically using the STATISTICA ver. 10 software package. The results were analysed statistically to establish mean values, standard deviation $( \pm \mathrm{SD})$ and correlation coefficients. All analyses were conducted in three independent replications.

\section{RESULTS AND DISCUSSION}

The pigment preparation precipitated from beet juice had a lower content of yellow pigments than the juice, and the ratio between the content of violet and yellow pigments decreased from 1:0.42 to 1:0.25 in the finished preparation (Figure 1). A comparison of areas determined for individual peaks generated by betalain pigments in the juice and in the solution of the preparation, obtained by HPLC-based analytical separation of both samples, is shown in (Figure 1). 


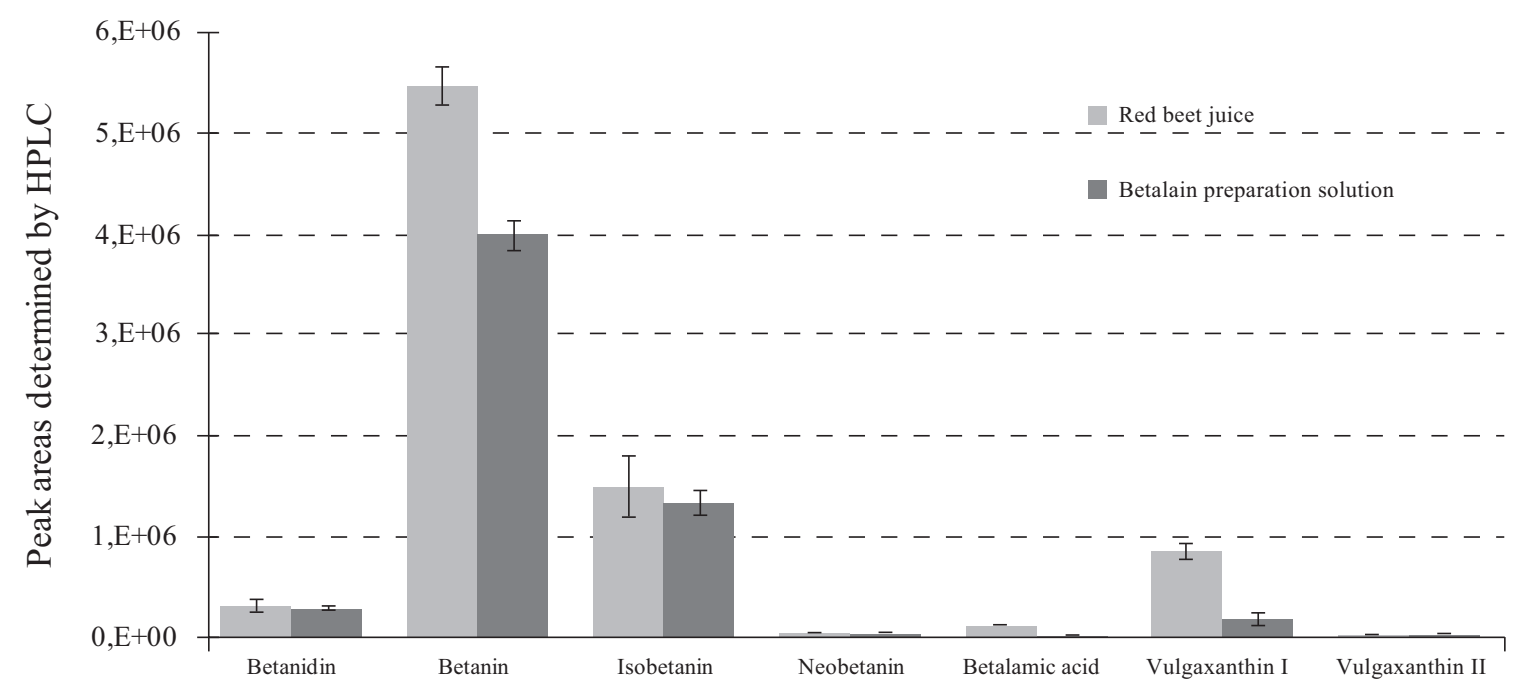

FIGURE 1. Peak areas shown in HPLC chromatograms at $\lambda=540 \mathrm{~nm}$ for betanidin, betanin and isobetanin; $\lambda=480$ for neobetanin and vulgaxanthin I and II; and $\lambda=405 \mathrm{~nm}$ for betalamic acid - in juice and in the betalain preparation solution.

\section{The effect of pH on changes in the content of betalain pigments}

During the process of heating, the content of violet pigments assessed by Nilsson's method decreased. The losses of red pigments in the betalain preparation solution increased along with rising $\mathrm{pH}$ levels. The degradation of red pigments induced by the heating of the betalain preparation solution was the most pronounced at the $\mathrm{pH}$ of 9.0 , and amounted to 94\% compared to the unheated solution (Table 1).

Betanin is stable in mildly acidic solutions in which the $\mathrm{pH}$ level ranges from 4.0 to 6.0 [Von Elbe et al., 1974], whereas the stability of vulgaxanthins (yellow pigments) rises slightly in the $\mathrm{pH}$ range from 4.0 to 7.0 [Herbach et al., 2006]. The optimum environmental $\mathrm{pH}$ level ensuring the stability of betaxanthins is, however, 5.5 [Cai et al., 2001].

The process of thermal degradation of betalain pigments depends to a very large extent on the $\mathrm{pH}$ of the environment. Betanin and its aglycone betanidin are unstable when heated in oxygen conditions [Herbach et al., 2006; Pasch \& Elbe, 1979].

In this study, the content of yellow pigments in the solution of betalain pigments after heating, determined with Nilsson's method, was found to have increased. The most distinct increase was noted at the $\mathrm{pH}$ of 6.5 and 7.0, reaching $31 \%$ and $21 \%$, respectively, as compared to the content of yellow pigments in the solution before heating.

The increase in the content of yellow pigments which was determined by Nilsson's method in heated samples is a result of accumulation of products of betacyanin transformations, e.g. the process of dehydrogenation involving the decomposition of red pigments and the emergence of compounds absorbing light at the wavelength of $480 \mathrm{~nm}$ which are products of transformations of betacyanins (red pigments).

Nilsson's spectrophotometric method is used for determining the total content of betacyanins and the total content of betaxanthins taking into account extinction coefficients: 1120 for betanin at the wavelength of $538 \mathrm{~nm}$ and 750 for vulgaxanthin at the wavelength of $470 \mathrm{~nm}$ [Piattelli \& Minale, 1964]. It must be noted, though, that the method was de- veloped for assaying yellow and violet pigments in unheated juice, i.e. in samples containing unchanged pigments.

In an analysis of pigment degradation, especially as a result of high temperatures, the method is biased because extinction coefficients for betacyanins arising during pigment processing are unknown [Nemzer et al., 2011].

The total betacyanin and betaxanthin concentrations were determined by the spectrophotometric method [Nilsson, 1970]. Additionally, the analysis of the particular betalains was performed by the HPLC method. The results obtained by the Nilsson's method, especially for the yellow pigments, should be regarded as a rough estimation due to the presence of various betacyanin derivatives of unknown extinction coefficients. Because the profiles of the betalain pigments could change during the heating of the betalain preparation solutions, it was decided to analyse the sample by HPLC method to determine the changes of the betalain profiles after heating.

\section{Changes in the antioxidant activity of betalain pigments during heating}

The antioxidant capacity decreased in heated samples to a much lesser extent than the content of red pigments (Table 1). Antioxidant capacity losses observed during the heating of the betalain preparation solution with the $\mathrm{pH}$ range from 4.0 to 9.0 amounted to $16-22 \%$ depending on the $\mathrm{pH}$ of the solution.

As for the antioxidant capacity of the heated betalain preparation expressed per milligram of red pigments, it was found to increase with $\mathrm{pH}$ rise (Table 1).

After the heating of the betalain preparation solution with the $\mathrm{pH}$ of 4.0 , the antioxidant capacity expressed per milligram of violet pigments increased from 13.5 to $16.4 \mu \mathrm{mol}$ Trolox. For the solution with the $\mathrm{pH}$ of 9.0, the corresponding value was $175.3 \mu \mathrm{mol}$ Trolox. These data show that the significant increase in the antioxidant capacity during the heating of solutions could be due to the presence of products of their decomposition or transformations. The study demonstrated a decreased content of betanin and an increased content of neobetanin during heating (Figure 2), which is indicative 
TABLE 1 . The effect of $\mathrm{pH}$ on changes in the content of betalain pigments and antioxidant capacity determined by ABTS in the betalain preparation solution during heating.

\begin{tabular}{|c|c|c|c|c|c|c|}
\hline \multirow{2}{*}{ Sample } & \multirow{2}{*}{$\mathrm{pH}$} & \multicolumn{2}{|c|}{ Betalain content* $(\mathrm{mg} / \mathrm{mL})$} & \multirow{2}{*}{$\mathrm{V} / \mathrm{Y}$} & \multicolumn{2}{|c|}{ TEAC } \\
\hline & & violet & yellow & & $\mu \mathrm{mol}$ Trolox $/ \mathrm{mL}$ & $\begin{array}{c}\mu \text { mol Trolox/ } \\
\text { mg violet pigment }\end{array}$ \\
\hline Unheated & 6.7 & $1.28 \pm 0.02$ & $0.32 \pm 0.02$ & 4.01 & $17.4 \pm 0.16$ & 13.5 \\
\hline \multirow{7}{*}{ Heated $^{* *}$} & 4.0 & $0.76 \pm 0.01$ & $0.27 \pm 0.01$ & 2.82 & $12.6 \pm 0.22$ & 16.4 \\
\hline & 5.0 & $0.77 \pm 0.02$ & $0.31 \pm 0.02$ & 2.42 & $14.2 \pm 0.28$ & 18.4 \\
\hline & 6.0 & $0.72 \pm 0.02$ & $0.32 \pm 0.03$ & 2.21 & $14.9 \pm 0.17$ & 20.7 \\
\hline & 6.5 & $0.37 \pm 0,01$ & $0.42 \pm 0.02$ & 0.86 & $14.2 \pm 0.20$ & 38.2 \\
\hline & 7.0 & $0.26 \pm 0.01$ & $0.39 \pm 0.02$ & 0.66 & $13.7 \pm 0.39$ & 52.5 \\
\hline & 8.0 & $0.10 \pm 0.03$ & $0.34 \pm 0.01$ & 0.31 & $13.8 \pm 0.31$ & 130.6 \\
\hline & 9.0 & $0.07 \pm 0.02$ & $0.31 \pm 0.01$ & 0.25 & $13.7 \pm 0.40$ & 175.3 \\
\hline
\end{tabular}

${ }^{*}$ Content of betalain pigments determined with the Nilsson's method; **Samples heated at $90^{\circ} \mathrm{C}$ for $30 \mathrm{~min} ; \pm$ standard deviation; V/Y - Violet pigment to yellow pigment ratio.

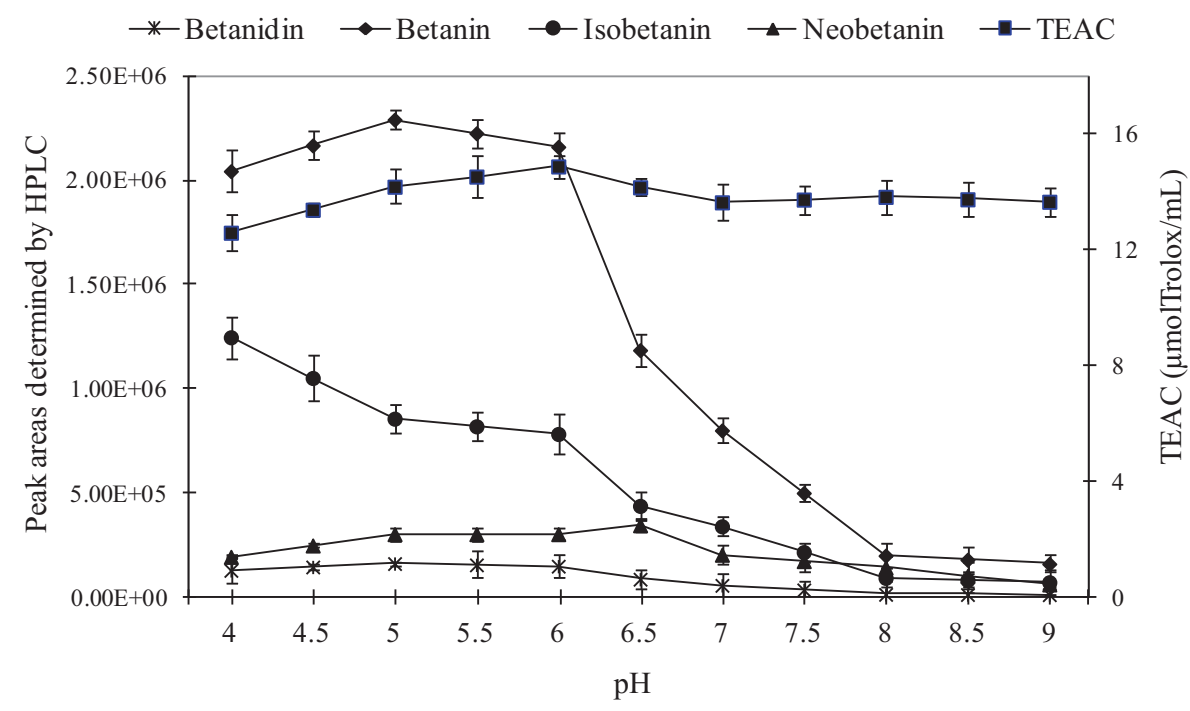

FIGURE 2. The effect of $\mathrm{pH}$ on changes in antioxidant capacity and HPLC peak areas during the heating $\left(90^{\circ} \mathrm{C} / 30 \mathrm{~min}\right)$ of the betalain preparation solution with the $\mathrm{pH}$ from 4.0 to 9.0 .

of the high antioxidant activity of betanin products, including neobetanin and/or other yellow betanin derivatives.

A review of HPLC chromatograms recorded for the heated betalain solution with the $\mathrm{pH}$ in the range from 4.0 to 9.0 made it possible to assess changes in the content of different pigments during heating. As the $\mathrm{pH}$ level of the betalain preparation solutions increased, the content of betanin and isobetanin was gradually decreasing after heating (Figure 2).

Particularly noticeable losses of these pigments while heating were noted when the betalain preparation solution had the $\mathrm{pH}$ level of 6.5 and higher. Increased $\mathrm{pH}$ values were also conducive to the accumulation of neobetanin (Figure 2). The greatest accumulation of the compound was observed at the $\mathrm{pH}$ of $6.0-7.0$, i.e. close to the natural $\mathrm{pH}$ level of juice.

However, the observed effect of $\mathrm{pH}$ on the antioxidant capacity of heated betalain preparation solutions with the $\mathrm{pH}$ from 4.0 to 9.0 was minor (Figure 2).
The increase in the content of yellow pigments during heating, as determined with Nilsson's method, is also linked with the presence of neobetanin. Neobetanin $\left(5-O-\beta-{ }_{\mathrm{D}}\right.$-glucopyranosyl neobetanidin or 14, 15-dehydrobetanin) has been identified as a new class of orange pigments belonging to the betalain group [Alard et al., 1985] in multiple plants of the order Caryophyllales. In 2004, Herbach et al., were the first to report that the pigment was a product of thermal degradation of betanin, arising during the heating of red beet juice. In spite of its orange colour $\left(\lambda_{\max }=465\right.$ or $470 \mathrm{~nm}$ based on Stintzing et al. [2004] and Herbach et al. [2006]; $\lambda_{\max }=474 \mathrm{~nm}$ based on own study), neobetanin is structurally classified as one of the betacyanins (red pigments).

The $\mathrm{pH}$ level has a major influence on changes in the antioxidant capacity of different pigments during heating. The increasing $\mathrm{pH}$ value of the heated betalain preparation solution was correlated with losses of betanin $\left(\mathrm{R}^{2}=0.86\right)$, betanidin 

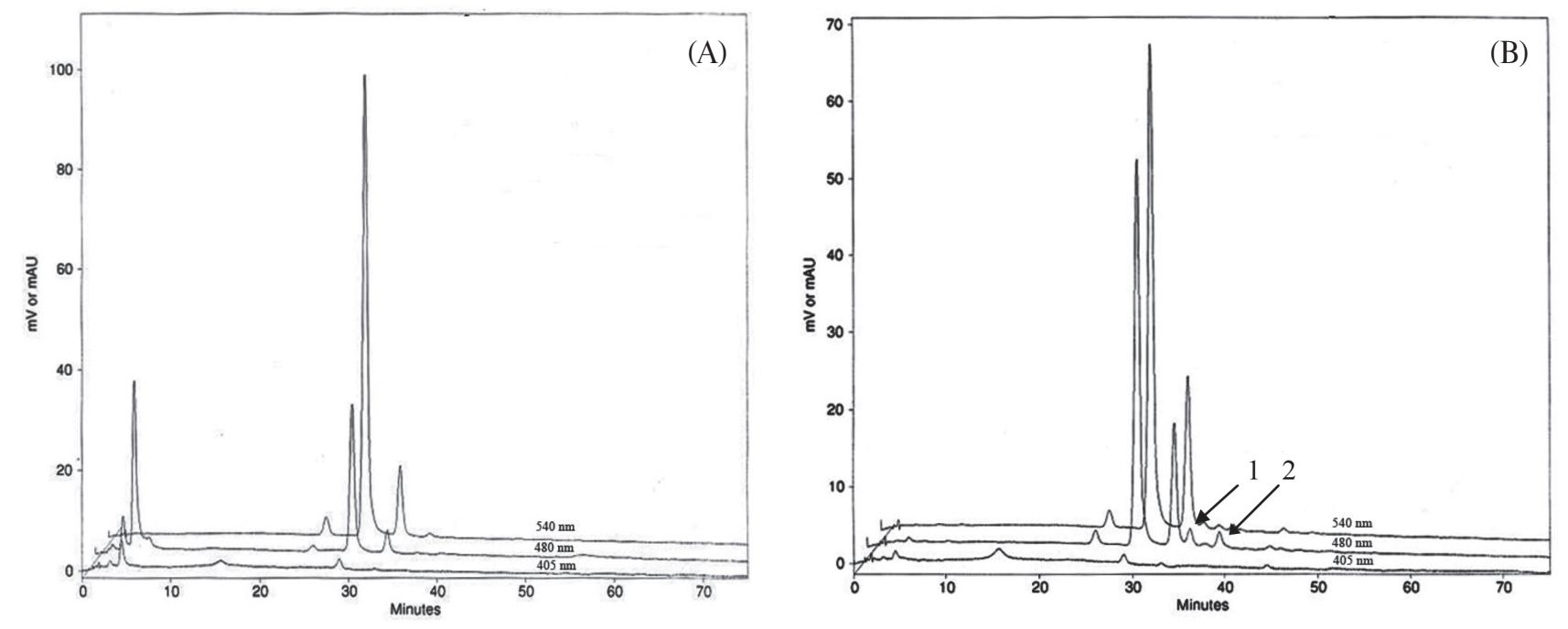

FIGURE 3. HPLC chromatogram of the betalain preparation solution with the $\mathrm{pH}$ of $6.0 ; \mathrm{A}-\mathrm{unheated}, \mathrm{B}-\mathrm{heated}\left(90^{\circ} \mathrm{C} / 30 \mathrm{~min}\right), 1-\mathrm{neobetanin}$, 2 - yellow betanin derivative.

$\left(\mathrm{R}^{2}=0.82\right)$, isobetanin $\left(\mathrm{R}^{2}=0.95\right)$, but was not correlated with the content of neobetanin $\left(\mathrm{R}^{2}=0.22\right.$, statistically insignificant). The $\mathrm{pH}$ range of 5.0-6.5, on the other hand, was associated with a significant increase in neobetanin concentration.

Degradation products of betalain pigments induce a change in colour of the heated betalain pigment solution, and hence contribute to an increased content of yellow pigments determined spectrophotometrically using the Nilsson's method. Samples affected by betalain degradation must be analysed by HPLC, since the technique offers an opportunity to precisely determine the losses of red and yellow pigments after heating in qualitative terms, and to keep track of the changes which occur in red beet pigments during heating. While studying the chromatograms shown in Figure 3, by peak area comparison of unheated betalain pigment solution and heated betalain pigment solution with the $\mathrm{pH}$ of 6.0 , the new peaks at a wavelength of $480 \mathrm{~nm}$ have appeared. The first peak $(\mathrm{tr}=36 \mathrm{~min})$ corresponds to the neobetanin, and the second to yellow betanin derivative $(\mathrm{tr}=39 \mathrm{~min})$. Studies conducted by other authors [Nemzer et al., 2011], indicate that during thermal treatment - as a result of decarboxylation or dehydrogenation - betanin (a purple pigment found in greatest amounts in beets) is transformed into neobetanin and/or its derivatives (yellow-orange pigments), which due to their chemical structure are classified as purple pigments (betacyanins). Neobetanin and its derivatives show maximum light absoprtion within the range from 420 to $480 \mathrm{~nm}$, i.e. they are yellow-orange in colour, despite being classified to the group of purple betacyanins, as it results from their chemical structure [Nemzer et al., 2011].

\section{CONCLUSION}

Violet pigments losses occurring in the process of heating of the betalain preparation solution increased along with rising $\mathrm{pH}$ levels. Changes in violet pigments content were found to be correlated with the $\mathrm{pH}$ of $4.0-9.0\left(\mathrm{R}^{2}=0.86\right)$. Heating of the betalain preparation solution caused an increase in the content of yellow pigments (determined spectrophotometrically using the Nilsson's method). Changes in their content were found to be correlated with the $\mathrm{pH}$ level. The greatest increase in the content of these pigments was observed at $\mathrm{pH}$ of 6.5 and 7.0. Changes in yellow pigments content were found to be correlated with the $\mathrm{pH}$ range from 6.5 to $9.0\left(\mathrm{R}^{2}=0.98\right)$. The increasing $\mathrm{pH}$ value of the heated betalain preparation solution was linked with increased losses of betanin, betanidin and isobetanin assessed by HPLC. At the same time, neobetanin accumulation was observed, most distinctly at the $\mathrm{pH}$ of 6.5 .

Although violet pigments were affected by a nearly complete degradation $(94 \%$ in the heated betalain preparation solution with the $\mathrm{pH}$ of 9.0), the antioxidant capacity of the solution decreased by only $21 \%$; expressed in terms of the content of violet pigments, antioxidant capacity rises with the $\mathrm{pH}$.

During the process of heating, the antioxidant capacity of the solution was subject to minor changes across the entire $\mathrm{pH}$ range, i.e. from 4.0 to 9.0 , while violet pigment losses increased along with the $\mathrm{pH}$, particularly when the $\mathrm{pH}$ was above 6.0 .

\section{RESEARCH FUNDING}

The study was financed by the National Science Centre, under project. No. DEC-2012/07/B/NZ9/00047.

\section{CONFLICT OF INTEREST}

Authors declare no conflict of interest.

\section{REFERENCES}

1. Alard D., Wray V., Grotjahn L., Reznik H., Strack D., Neobetanin: isolation and identification from Beta vulgaris. Phytochemistry, 1985, 24, 2383-2385.

2. Cai Y., Sun M., Schielmann W., Corke H., Chemical stability and colorant properties of betaxanthin pigments from Celosia argentea. J. Agric. Food Chem., 2001, 49, 4429-4435. 
3. Czapski J., Mikołajczyk K., Kaczmarek M., Relationship between antioxidant capacity of red beet juice and contents of its betalain pigments. Pol. J. Food Nutr. Sci., 2009, 59, 119-122.

4. Herbach K.M., Stintzing F.C., Carle R., Betalain stability and degradation - structural and chromatic aspects. J. Food Sci., 2006, 71, R41-R50.

5. Herbach K.M., Stintzing F.C., Carle R., Impact of thermal treatment on color and pigment pattern of red beet (Beta vulgaris L.) preparations. Food Chem. Toxicol., 2004, 69, C491-C498.

6. Kanner J., Harel S., Granit R., Betalains - A new class of dietary cationized antioxidants. J. Agric. Food Chem., 2001, 49, 5178-5185.

7. Nemzer B., Pietrzakowski Z., Spórna A., Stalica P., Thresher W., Michałowski T., Wybraniec S., Betalainic and nutritional profiles of pigment-enriched red beet root (Beta vulgaris L.) dried extracts. Food Chem., 2011, 127, 42-53.

8. Nilsson T., Studies into the pigments in beetroot (Beta vulgaris L. ssp. vulgaris var. rubra L.). Lantbrukshogskolans Annaler., 1970, 36, 179-219.

9. Pasch J.H., Elbe J.H., Betanine stability in buffered solutions containing organic acids, metal cations, antioxidants, or sequestrants. J. Food Sci., 1979, 44, 72-74.

10. Pedreno M.A., Escribano J., Studying the oxidation and the antiradical activity of betalain from beetroot. J. Biol. Educ., 2000, $35,49-51$.
11. Piattelli M., Minale L., Pigments of centrospermae -II. Distribution of betacyanins. Phytochemistry, 1964, 3, 547-557.

12. Re R., Pellegrini N., Proteggente A., Pannala A., Yang M., Rice-Evans C., Antioxidant activity applying an improved ABTS radical cation decolorization assay. Free Radic. Biol. Med., 1999, 26, 1231-1237.

13. Stintzing F.C., Conrad J., Klaiber I., Beifuss U., Carle R., Structural investigations on betacyanin pigments by LC NMR and 2D NMR spectroscopy. Phytochemistry, 2004, 65, 415-422.

14. Stintzing F.C., Schieber A., Carle R., Identification of betalains from yellow beet (Beta vulgaris L.) and cactus pear [Opuntia ficus-indica (L.) Mill.] by high-performance liquid chromatography-electrospray ionization mass spectrometry. J. Agric. Food Chem., 2002, 50, 2303-2307.

15. Strack D., Vogt T., Schielmann W., Recent advances in betalain research. Phytochemistry, 2003, 62, 247-269.

16. Von Elbe J.H., Maing I.Y., Amundson C.H., Color stability of betanin. J. Food Sci., 1974, 39, 334-337.

17. Zakharova N.S., Petrova T.A., Relationship between the structure and antioxidant activity of various betalains. Prikl. Biokhim. Mikrobiol., 1998, 34, 199-202.

Submitted: 19 June 2015. Revised: 26 December 2015, 1 January and 8 January 2016. Accepted: 20 April 2016. Published on-line: 2 November 2016. 